\title{
Scientists 'must assert their independence'
}

London. Sir Michael Atiyah, one of Britain's leading mathematicians, ended his four-year term of office as the president of the Royal Society last week with an outspoken call for scientists "to criticize the establishment where necessary", and to "demonstrate that independence of thought really is the hallmark of a scientist".

True to his own counsel, he then attacked the support given since the Second World War by successive British governments to an independent nuclear deterrent. Atiyah claimed that this has been the root not only of the country's economic decline over that period but also of the hostile attitude of the general public towards science and the scientific community. He also expressed concern about the continuing role of scientists in the international arms trade.

At one point, Atiyah implicitly compared the dangers of the government's lack of support for basic science to those of Stalin's attitude towards the arts. But, in a move apparently intended to indicate political even-handedness, he also criticized hints in a recent Labour Party document that the society's receipt of public funds could be used as a possible lever to pressure it into appointing more women as fellows.

Atiyah was making his last formal statement before handing over to his successor, Sir Aaron Klug, the director of the Medical Research Council's Laboratory for Molecular Biology in Cambridge. He said that his

\section{CIA's psychic spies under scrutiny}

San Francisco. A \$20-million 20-year US government programme to employ and evaluate paranormal spying techniques has yielded results which, while not providing any firm evidence of psychic phenomena, can still be described as equivocal, according to two analysts who have reviewed the previously classified work.

Their conclusions are based on recently released data on the way various US government agencies secretly used up to six psychics at a time to help locate hostages, track down alleged terrorists and help drug enforcement officials. Experiments included studies on precognition, clairvoyance and "remote viewing", in which psychics visualized distant or hidden locations or objects.

The reviewers agreed that the results were statistically significant. But they disagreed on how they should be interpreted. Jessica Utts, a statistics professor at the University of California at Davis who is an advocate of parapsychology research, said they showed psychic phenomena as having had a small to medium-sized effect. But her collaborator, Ray Hyman, a psychology professor at the University of Oregon in Eugene, said that "inexplicable statistical

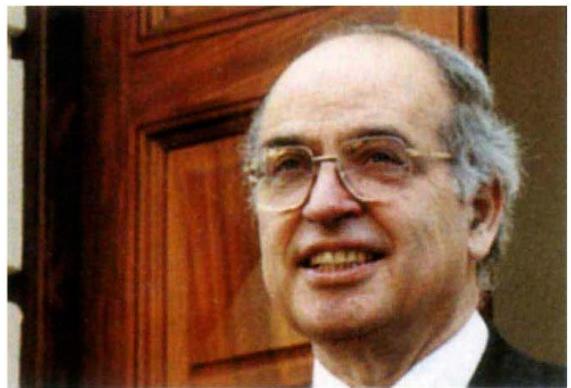

Atiyah: critical of the UK's nuclear deterrent.

remarks were prompted by concern that the scientific community is "in danger of losing our way and our identity" in the "semi-political" world in which it has to operate.

Referring, for example, to this year's fiftieth anniversary of the dropping of the atomic bomb, he emphasized how, for many scientists, this had demonstrated that "the ivory tower was no longer a sanctuary" and the public felt "atomic bombs were a menace and the scientists were responsible".

The crucial question now faced by scientists is how to conduct relations with government and industry so as to regain the public's confidence. Here some humility is needed. "It is no use complaining that the public is simply ill-informed and needs reeducating," said Atiyah. "We have to examine our own position and see whether any of the criticisms levelled against us are valid."

Even though scientists may constantly

departures from chance" were a far cry from compelling proof.

In the remote viewing studies, for example, a 'viewer' accurately drew a California windmill farm and the footbridge at a wildlife refuge visited by a 'sender' partner as many as 50 miles away.

The Central Intelligence Agency had asked Utts and Hyman to evaluate the project for the Senate Appropriations Committee. The programme, which employed three psychic agents as recently as July, has raised questions about appropriate government spending on research. The studies began as a response to concerns that a 'psychic gap' in military and intelligence prowess had developed with the Soviet Union.

Utts and Hyman agreed that the first era of research was problematic, with no controlled experiments and selectively chosen research results. But, they said, protocols improved greatly by the late $1980 \mathrm{~s}$. Utts, who had participated in some of the studies, said that future research should concentrate on how a psychic sense may work. But Hyman said more work is needed to determine whether psychic phenomena exist.

Sally Lehrman exercise a "benign influence" in the corridors of power, this will not impress a sceptical public. "Scientists are too often thought of as a secretive élite, a sinister part of the establishment, part of 'them' not part of 'us'," said Atiyah. "The only way to break down this suspicion and distrust is for scientists to speak out openly and freely."

For example, Atiyah predicted that, on the basis of comparisons with the recent histories of Germany and Japan, "history will show that the insistence on a UK nuclear capability was fundamentally misguided, and a significant factor in our relative economic decline over the past 50 years".

At the same time, despite promises of a 'peace dividend' at the end of the Cold War that was supposed to see the shift of resources from military to civilian research, Atiyah said that he had "failed to detect any conscious policy on the redistribution of scientific resources".

Meanwhile, the export of conventional armaments raises continued ethical problems for scientists. Atiyah said that he acknowledges the economic and employment advantages from such sales. "But as a scientist, I cannot by my silence condone a policy which uses the scientific skills of this country to export potential death and destruction to poorer parts of the world, where their scarce resources would be better employed on food and health."

Turning to contemporary science policy issues, Atiyah also warned that turning off resources for so-called 'blue-skies' research will encourage the creative scientific intellects needed for the future to migrate to other lands or other occupations.

The dangers of political pressure, he suggested, also emerge in proposals that the government should take steps to require the society to increase its women fellows. Atiyah pointed out that a number of steps have recently been taken to assist women scientists at various stages of their careers including a new fellowship scheme named after the Nobel prizewinner Dorothy Hodgkin - but said that it will take time for these measures to produce a larger flow of women candidates.

David Dickson - The holder of Britain's first chair in the public understanding of science claimed last week that there is a need to shift from a "top down" approach, based on the premise that the main need is merely to propagate scientific information more widely, to one that is "bottom up" as based on a dialogue between scientists and the public.

Delivering his inaugural address at Imperial College, London, John Durant - who is also an assistant director of London's Science Museum - said that those engaged in developing the public understanding of science need to adopt a new agenda, namely the creation of trust between the two sides. 